\title{
SHEAR STRENGTH OF THIN WEB - INFLUENCE OF LIGHTING OPENINGS AND DIAGONAL TENSION
}

\author{
Marek HORÁK, Antonín PÍŠTĚK \\ Brno University of Technology, Institute of Aerospace Engineering, Technická 2896/2 61669 Brno, \\ Czech Republic \\ E-mail: horak@fme.vutbr.cz (corresponding author)
}

Received 06 November 2014; accepted 02 March 2016

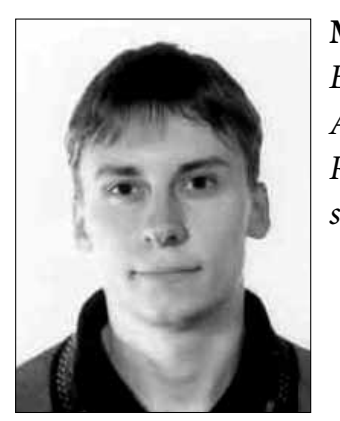

Marek HORÁK, Eng

Education: Brno University of Technology, Aircraft Design

Affiliation and functions: post-graduate student at Brno University of Technology since 2009. Research interests: aircraft design, stress analysis of aircraft structures, testing of aircraft structures.

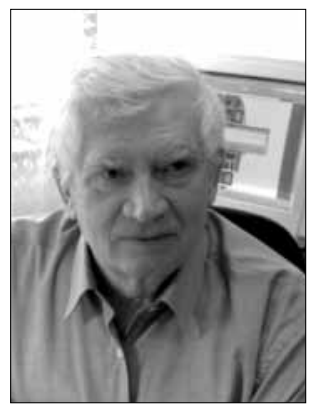

Antonín PÍšTĚK, Prof Eng CSc

Education: Military Academy of Brno, Aircraft Design

Affiliation and functions: Professor at Brno University of Technology (BUT). Deputy Director at the Institute of Aerospace Engineering (IAE).

Research interests: aircraft design, stress analyses of aircraft structures, mechanics, finite element methods, experimental stress analysis of aircraft structures.

Abstract. This article provides information about stress analysis of thin beam webs with and without lighting openings. The study described in this paper was carried out in order to investigate the influence of circular lighting openings in planar webs on critical web shear force, distribution of transverse web deformations, and also strain and stress distribution in the web plate. The main goal was to compare pre- and post-buckling behaviour of a thin web with and without lighting openings under shear load.

The procedure was as follows: first of all, seven specimens - beams with a different combination of parameters (web thickness, opening size and web dimension) were calculated using available analytical methods; secondly, the same specimens were produced and tested up to load near failure; thirdly, these specimens were analysed using the Finite element method; finally, the tests results were compared with results of numerical simulations.

Keywords: beam, thin web, lighting openings, stress, strain, buckling, diagonal tension, final element analysis.

\section{Introduction}

A beam with thin web is one of the basic structural elements in airframes of all aircraft types and sizes. In terms of load transfer, it is the most important structural element in the wing, tail units and control surfaces. Its importance largely corresponds to the proportion of its weight on the weight of a certain part of the aircraft. In comparison with other fields of engineering, the final weight of the aircraft structure is of very high importance. The weight reduction is precisely why aircraft engineers design thin-walled beams with web openings. However, in order to achieve maximum effect, it is necessary to use the latest scientific knowledge in this field. 
Despite of its importance in aircraft structures, the issue of critical load, the behaviour in the post-critical stage of loading and ultimate load capacity of this type of beams remains somewhat neglected. Some important research studies in this field have been executed in the past. One of the most important is an extensive study by American organization NACA (National Advisory Committee for Aeronautics) (Kuhn et al. 1952; Kuhn 1942), which was conducted during World War II and a few years after. Another important study was conducted in Russia at the same time. Later, these studies were followed by another one, referred to as Swedish research, which is also quite extensive. The results of several other studies, which were carried out several decades ago, can be found in some technical publications, which were written by Maddux et al. (1969), Niu (1999), and by the other authors (Singer et al. 2002; Čtverák et al. 1997; Píštěk et al. 1988). These publicly available methods have been further modified and supplemented by greater aircraft manufacturers in order to respect the latest knowledge thus enabling an even more efficient use of the material. However, these modified forms have not been published; therefore, other producers, especially small ones, cannot use them for the design of their own aircraft.

A modern approach to stress analysis of aircraft structures is based on the application of one of several available software packages which work on the principle of the Finite Element Method (FEM). However, to find a correct solution using this way may also be somewhat problematic, because thin-walled elements like web, stiffeners and flanges lose their stability. The necessary data and procedures which would lead to a correct solution are also unavailable.

The main objective of this study is the verification and provision of supplementary data to these available calculation methods for determining the ultimate load capacity of the spars with a thin web with or without circular web openings, which are commonly used in the design of small airplanes.

\section{Experimental investigation}

The initial phase of this study was focused on determining the fundamental parameters of the problem. Specifically, the basic shape, overall size and several other important dimensions of the specimens were determined. After that, a rigid construction of a test jig (frame and load distribution system) was designed in accordance with the desired way of specimen mounting and application of load. It was done in order to achieve a maximal compliance with the conditions in real aircraft structures.

The purpose of the experimental investigation is the validation of the results of currently available computational methods, their modification, and also attainment of the data necessary for the preparation of an adequate numerical model.

\subsection{Specimens and test jig}

In total seven different specimens were tested. The main dimensions of all specimens are identical (Fig. 1), but their structure is different in web thickness, diameter of web openings and number of stiffeners. A typical structure is shown in Figure 1.

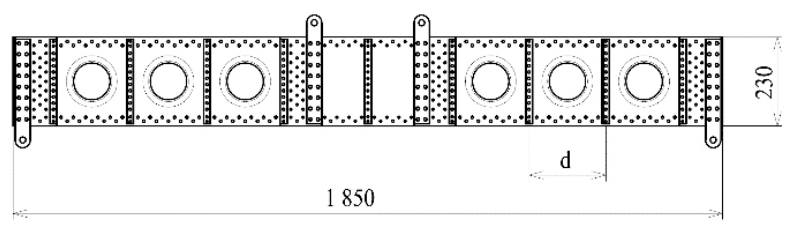

Fig. 1. Scheme of a specimen

The geometrical characteristics of the specimens are presented in Table 1, where:

$t \quad$... web thickness

$D$... diameter of web openings

$h_{e} \quad \ldots$ effective height of the beam

$d$... distance between stiffeners

Flanges are formed by one L-shape profile with a cross section area of $172 \mathrm{~mm}^{2}$. Single sided stiffeners are also formed by an L-shaped profile with a cross section area of $74.5 \mathrm{~mm}^{2}$ and $0.6 \mathrm{~mm}$ thin doublers are used only for web reinforcement on the edges of the areas which are examined. The geometry of openings corresponds to the Czech aviation standard LDN 1505.

Webs, doublers, flanges and stiffeners were made from aluminium alloys. Hinges were made from a steel plate. The connections between spars and hinges are realized using steel bolts, whereas solid aluminium rivets were used for all other connections.

Table 1. Geometrical characteristics of the specimens

\begin{tabular}{lllllll}
\hline $\begin{array}{l}\text { Spec. } \\
\text { no. }\end{array}$ & $\begin{array}{l}t \\
{[\mathrm{~mm}]}\end{array}$ & $\begin{array}{l}D \\
{[\mathrm{~mm}]}\end{array}$ & $\begin{array}{l}\text { he } \\
{[\mathrm{mm}]}\end{array}$ & $\begin{array}{l}d \\
{[\mathrm{~mm}]}\end{array}$ & $\begin{array}{l}\text { he/t } \\
{[-]}\end{array}$ & $\begin{array}{l}\text { D/he } \\
{[-]}\end{array}$ \\
\hline 1A & 0.6 & - & 213 & 200 & 355 & - \\
\hline 1B & 0.6 & 63.5 & 213 & 200 & 355 & 0.30 \\
\hline $1 \mathrm{C}$ & 0.6 & 96.0 & 213 & 200 & 355 & 0.45 \\
\hline 1D & 0.6 & - & 213 & 300 & 355 & - \\
\hline 1E & 0.6 & - & 213 & 150 & 355 & - \\
\hline 2C & 0.8 & 96.0 & 213 & 200 & 266 & 0.45 \\
\hline 3C & 1.0 & 96.0 & 213 & 200 & 213 & 0.45
\end{tabular}

The specimens were attached to the test jig at both ends by hinges. On one side of the specimen, only the rotation about the pivot axis, which is perpendicular to the plane of the web, is allowed. On the other side of the specimen, the same rotation and the horizontal displacement in the plane of the web are allowed. This way of attachment ensures a real deformation of the specimens 


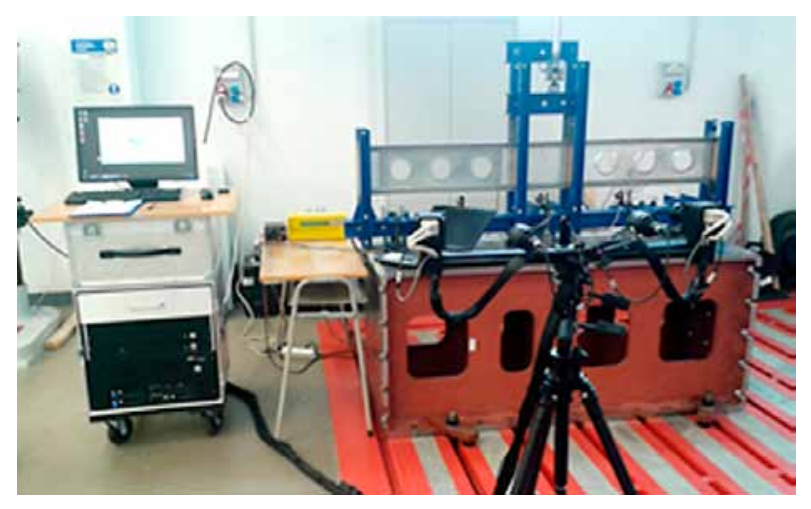

Fig. 2. Specimen in the test jig before the test

during tests. Furthermore, to ensure the boundary conditions approximately corresponding to real wing structures, four guiding frames were used. These frames were used to prevent unwanted rotation and out of web plane displacement of the cross section in places where the specimens are attached to the test jig and also in places where the specimens are connected to the load distribution system. For the purpose of loading, only one hydraulic actuator, which is connected to the load distribution system, was used. The load distribution system was connected to two inner hinges and distributed the total load evenly to both symmetrical halves of the specimens.

The structure of the test jig is shown in Figure 2. The main purpose of the test jig is to ensure the correct boundary conditions and simultaneously correct the application of load to the structure.

\subsection{Measured parameters}

During tests, the total load, strains in the web, in the flanges and in one of the stiffeners and also the deflection of the beam were measured. For measuring the strains in the web, two independent measuring systems were used - strain gauges and the photogrammetric system ARAMIS. All strains were measured in the areas marked in Figure 3. This figure also show three sections in which the deflection of the beam was measured. Strain gauges were placed near a central web field on one half of the specimen, while the ARAMIS system was used for measuring strains in three web fields on the second half of the specimen.

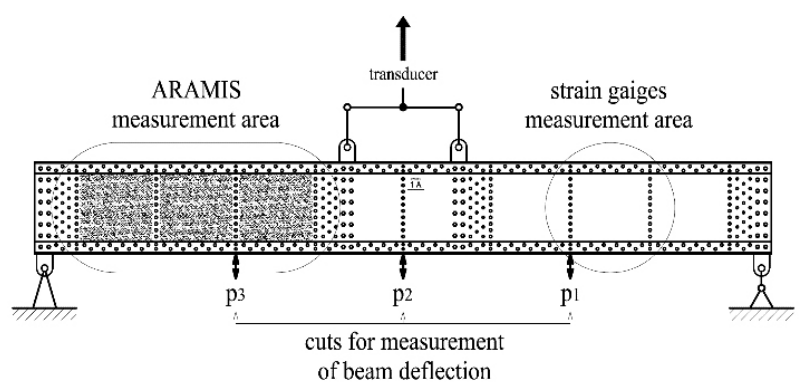

Fig. 3. Arrangement of the measuring equipment

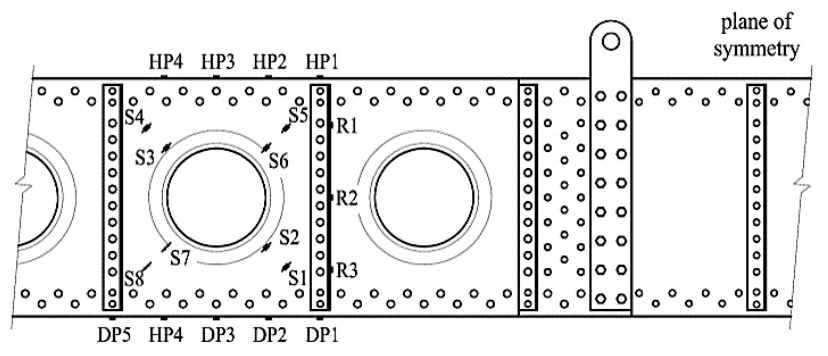

Fig. 4. Position of strain gauges (view on side B)

Sixteen strain gauges were placed on the web, eight on the front (side A) and eight on the back (side B) of the specimen. These strain gauges were installed for the purpose of determining the influence of openings on the diagonal tension field in a buckled web during the post-critical stage of loading. The next four strain gauges were placed on the upper flange, the same number of strain gauges was placed on the lower flange and three strain gauges were placed on one stiffener. These eleven strain gauges measured additional loads, which were caused by the diagonal tension field. The position and marking of strain gauges is shown in Figure 4.

The data from the transducer, strain gauges and linear variable displacement transducers was recorded using the data acquisition system ESAM CF.

\subsection{Test procedure}

The same procedure was used for all specimens. A small trial load, of approximately $20 \%$ of the expected ultimate web shear load was applied so that the beam was seated properly. Simultaneously, the transducer and strain gauges were checked for proper functioning. After that, the load was removed, readings were initialized and the beam was tested with several predetermined levels of load. Each specimen was tested up to more than $200 \%$ of the expected ultimate web shear load. Only four specimens were tested up to beam failure. During the tests, the transducer, strain gauge and the ARAMIS system readings were recorded.

\section{Finite element analysis (FEA)}

The aim of numerical simulations was to find such a finite element model which would lead to almost the same results as in the case of experimental investigation. For finite element analysis, the MSC Patran / MSC Nastran software package was used. The influence of these parameters on the conformity of results was analysed in a parametrical study:

- type of elements;

- size of elements;

- initial geometrical imperfection;

- type of solver. 


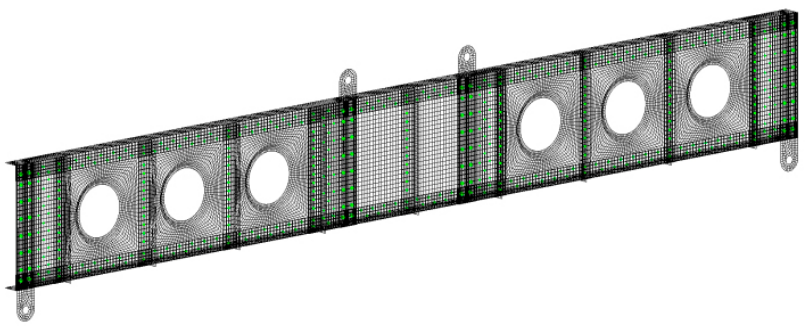

Fig. 5. Finite element model

The finite element model which is described in this chapter was chosen from several different variants as the most appropriate model.

The beams were modelled using $1 \mathrm{D}$ beam and $2 \mathrm{D}$ shell elements only. The geometry of each model corresponds to the real geometry of the produced specimens. Components such as web, doublers, flanges, stiffeners and hinges were represented using 2D shell elements, while all connections (rivet and screw joints) were represented using $1 \mathrm{D}$ beam elements. The mesh with a global element size of $7 \mathrm{~mm}$ was used for meshing the web with or without openings, doublers, flanges, stiffeners and hinges. Each element had its real properties defined, such as thickness in case of a 2D element or diameter in case of a 1D element. A finite element model of specimen $3 \mathrm{C}$ is shown in Figure 5. Linear-elastic material with correct properties was used in the model.

The boundary conditions which were applied in the numerical model correspond to those in practical experiments. The outer hinges on one side of the specimen only allowed the rotation around a pivot axis, and an outer hinge on the other side of the specimen allowed the rotation around a pivot axis and also its displacement along the span of the spar. Both outer and inner hinges were prevented from moving out of the web plane. The total load was divided into two equal forces, which were applied to the inner hinges. The influence of initial geometrical imperfection is, for this type of task, insignificant; therefore, it can be negligible. For the finite element analysis of this thin-walled structure, the nonlinear static analysis SOL106 is the best compromise between achieved accuracy and required computational time.

\section{Results and discussion}

\subsection{Evaluation of the measurement}

Maximal shear forces which were achieved during the test of individual specimens are specified in Table 2. In this table, the theoretical values of buckling web shear force and ultimate web shear force are noted. Ultimate web shear forces (expected ultimate load) were determined on the basis of diagrams in (Štverák et al. 1997). The parameters in Table 2 have the following meaning:

$T_{c r} \quad \ldots$ theoretical web buckling shear force;

$T_{\text {ult }} \ldots$ theoretical ultimate web shear force;

$T_{\text {test }} \ldots$ maximal shear force during a test.
Table 2. Summary of relevant loads for all specimens

\begin{tabular}{lllllll}
\hline $\begin{array}{l}\text { Spec. } \\
\text { no. }\end{array}$ & $\begin{array}{l}\text { Tor } \\
{[N]}\end{array}$ & $\begin{array}{l}\text { Tult } \\
{[N]}\end{array}$ & $\begin{array}{l}\text { Ttest } \\
{[N]}\end{array}$ & $\begin{array}{l}\text { Ttest/Tcr } \\
{[-]}\end{array}$ & $\begin{array}{l}\text { Ttest/Tult } \\
{[-]}\end{array}$ & $\begin{array}{l}\text { Tested to } \\
\text { failure? }\end{array}$ \\
\hline 1A & 1080 & 6260 & 12546 & 11.62 & 2.00 & no \\
\hline 1B & 1080 & 3930 & 9110 & 8.44 & 2.32 & no \\
\hline 1C & 1080 & 2810 & 9000 & 8.34 & 3.20 & no \\
\hline 1D & 910 & 5280 & 13080 & 14.46 & 2.48 & yes \\
\hline 1E & 1450 & 6880 & 15837 & 10.92 & 2.30 & yes \\
\hline 2C & 2530 & 4080 & 10739 & 4.25 & 2.63 & yes \\
\hline 3C & 4880 & 6300 & 13383 & 2.74 & 2.12 & yes \\
\hline
\end{tabular}

Figure 6 shows specimen 1D after unloading. In the case of this specimen, the maximal shear force which was achieved during the test represents $248 \%$ of the theoretical ultimate web shear load. This force is more than 140 times higher than the web critical load in shear. Although the web was not torn and material failure did not occur, this load caused a clearly visible residual deformation of the web caused by diagonal tension. This specimen was not tested up to failure.

One of the specimens which were tested up to failure was specimen $3 \mathrm{C}$. Figure 7 shows the typical structural failure of specimens $1 \mathrm{C}, 1 \mathrm{D}, 2 \mathrm{C}$ and $3 \mathrm{C}$. This failure was a local instability of a compression flange caused by the beam bending. Nevertheless, this type of failure occurred at a load which is significantly higher than the expected ultimate web shear load and also higher than the load which leads to the residual deformation of the web plate.

As mentioned above, two independent systems were used for the measurement of strains. Some of the measured values are compared in Figure 8. Generally, when the

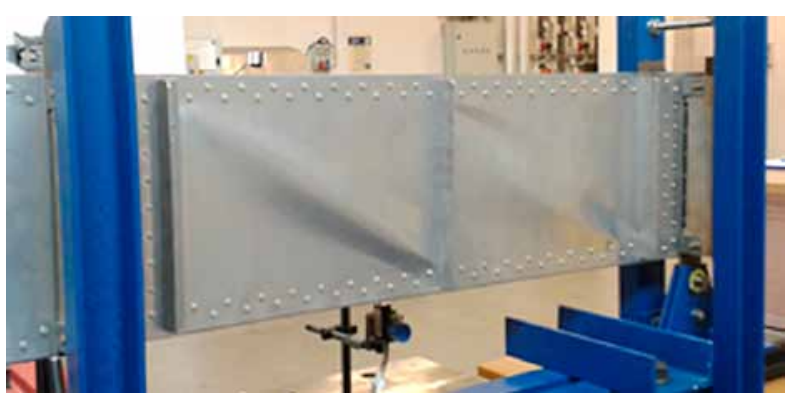

Fig. 6. Specimen 1D, residual deformation after the test

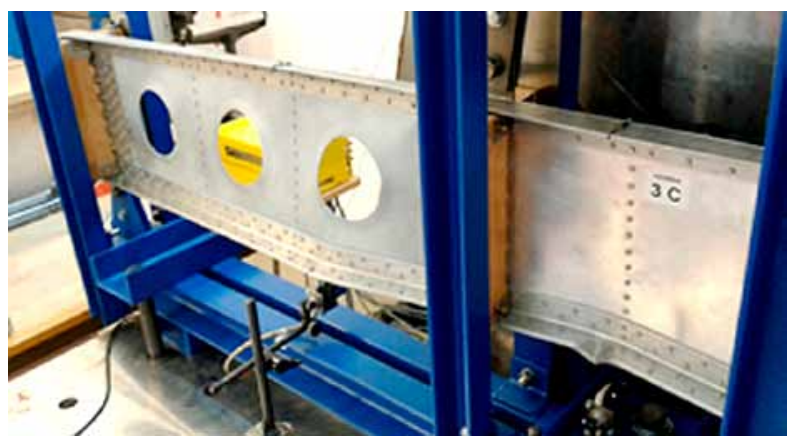

Fig. 7. Specimen $3 \mathrm{C}$ after the test 
calibration of the measuring equipment is performed properly, the values of strains measured using strain gauges and values which were measured by the ARAMIS system are almost identical. The differences that can be seen in Figure 8 are caused by the fact that the ARAMIS system is used on the other side of the specimen than the strain gauges. Small differences can also be caused by the reading accuracy of the individual values from the ARAMIS system.

Another possible way of representing the data from the ARAMIS system is shown in Figure 9. This example is a visualization of the Mises strain on the web surface of specimen $1 \mathrm{C}$ during test. The figure clearly shows a diagonal tension field in the web plate. This gives a very good idea about the web strain state in a global perspective and it is especially useful when searching for areas with the maximal values of strain.

It is very suitable to use the optogrammetrical system ARAMIS for investigating the post-buckling behaviour of thin walled structures, which are widely used in aircraft structures, because this system is able to measure strains and displacements on a large area simultaneously. However, this system is only applicable for measuring such parts of a structure that has a sufficiently large and smooth surface without abrupt changes in geometry. This measuring equipment is unusable for measuring stresses in flanges and stiffeners, because the large number of rivets makes it impossible to record the necessary data. These structural elements have to be measured using strain gauges.

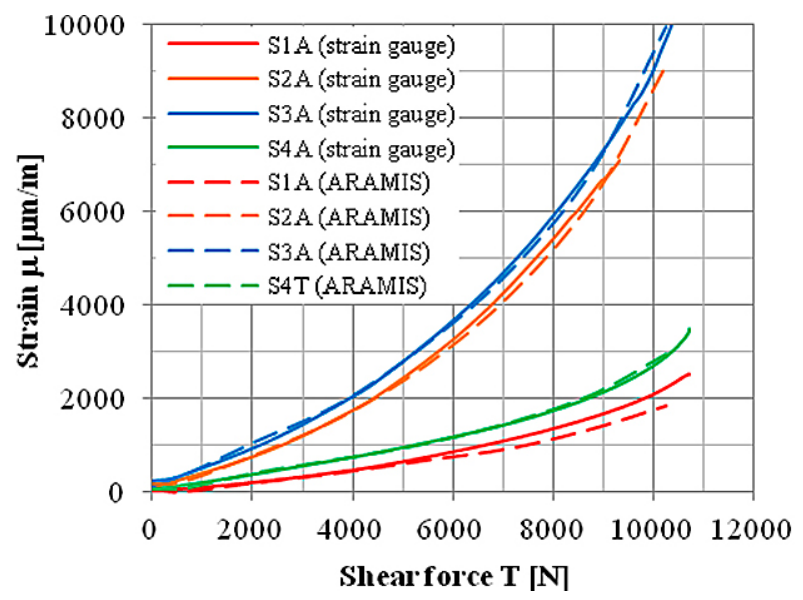

Fig. 8. Data from strain gauges and the ARAMIS system

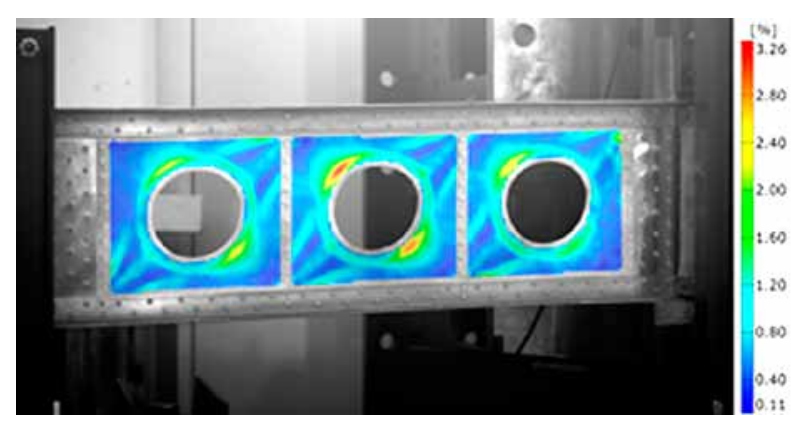

Fig. 9. Mises strain (beam 1C, side A, T=9000 N)

\subsection{Comparison of the measurement and FEA}

The deflections of all seven tested specimens at sections p2 (Fig. 3) depending on applied shear force are shown in Figure 12. In this diagram, the same parameters which were determined on the basis of finite element analysis described above are also shown. A very good correlation between the results of practical experiments (test) and numerical calculations (FEM) is evident. The maximal difference is seven percent for specimen $1 \mathrm{D}$ and less than four percent for other specimens.

Similar differences were obtained by comparing the measured and calculated values of the static strength of specimens 1D, 1E, 2C and 3C. The calculated values as well as their comparison with measured values are presented in Table 3.

Figure 11 shows an example of the Major strain distribution on the web surface at load, which is higher than the web buckling load. The strains, which were measured during the experiment using the system ARAMIS are shown on the left side, whereas stresses, which were calculated using the finite element method are shown on the right side of the figure. Both results are almost identical.

The facts mentioned above confirm that the numerical model used for the analysis lead to results that were accurate enough for their further evaluation.

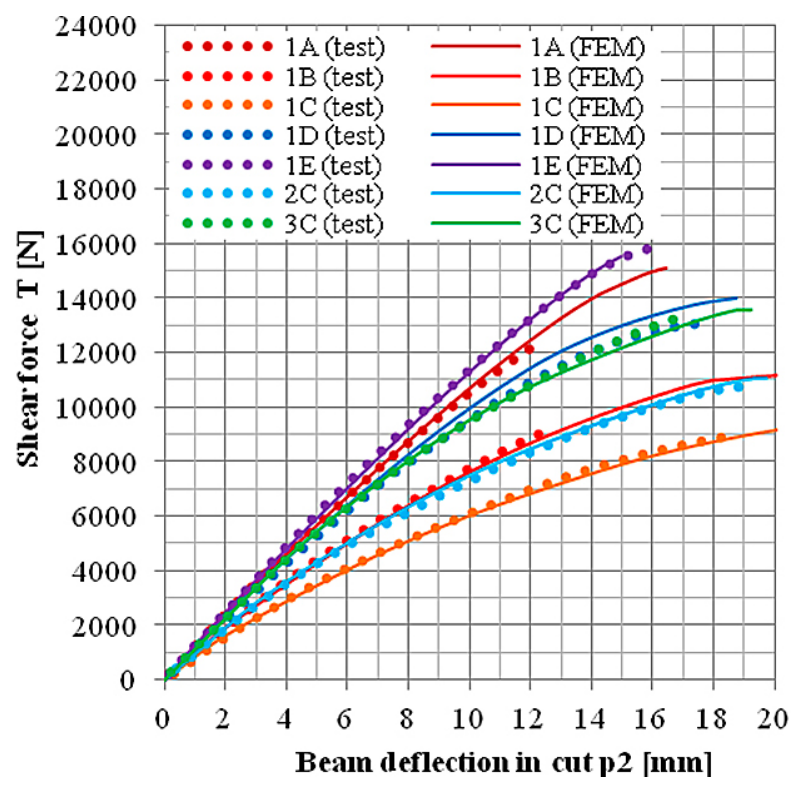

Fig. 10. Deflections of specimens: test vs FEA
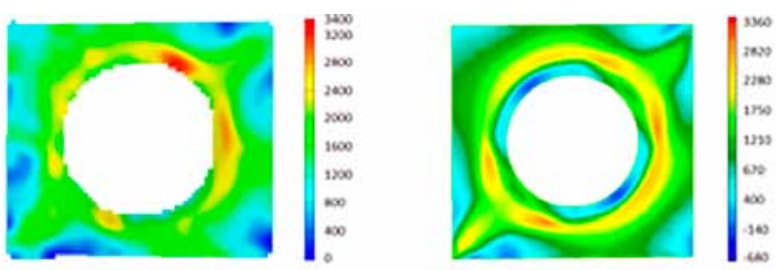

Fig. 11. Major strain (beam 1C, $\mathrm{T}>\mathrm{T}_{\mathrm{cr}}$ ) 


\subsection{Evaluation of the finite element analysis}

In terms of aircraft structure design, achieving the material ultimate strength of the webs of the examined thin beam is not a limiting factor for their sizing. For sizing of this type of structures, it is much more important to know the load in which the maximal stress in the structure is equal to material yield stress.

The process for obtaining this load in the thin web of the beam is shown in Figure 12. The diagram represents a typical web shear load vs the maximal web stress curve. The stress may be either shear stress or Mises stress; it does not matter.

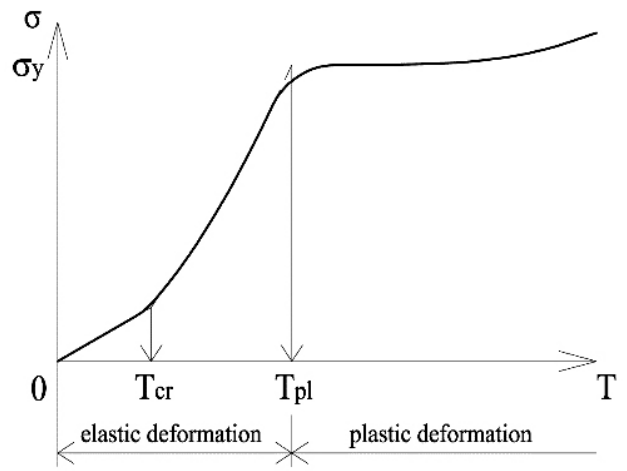

Fig. 12. Typical shear load - the maximal web stress curve

This curve has two characteristic points, at which the slope of the curve changes. The first point represents the critical web buckling load $\left(T_{c r}\right)$, whereas the second point represents load at which the material yield stress in the web is reached, i.e. the plastic deformation in the web plate occurs at load $T_{p l}$. Both values for all seven tested specimens are given in Table 3, where:

$T_{F E M} \ldots$ maximal shear force from FEA;

$T_{c r} \quad \ldots$ web buckling shear force from FEA;

$T_{p l} \ldots$ shear force at first plastic deformation from FEA.

Table 3. Results of finite element analysis

\begin{tabular}{lllll}
\hline $\begin{array}{l}\text { Spec. } \\
\text { no. }\end{array}$ & $\begin{array}{l}\text { TFEM } \\
{[N]}\end{array}$ & $\begin{array}{l}\text { TFEM/Ttest } \\
{[\%]}\end{array}$ & $\begin{array}{l}\text { Tcr } \\
{[N]}\end{array}$ & $\begin{array}{l}\text { Tpl } \\
{[N]}\end{array}$ \\
\hline $1 \mathrm{~A}$ & 15122 & 120.5 & 1150 & 6400 \\
\hline $1 \mathrm{~B}$ & 11157 & 122.5 & 1150 & 4650 \\
\hline $1 \mathrm{C}$ & 9836 & 109.5 & 1100 & 3750 \\
\hline $1 \mathrm{D}$ & 14032 & 107.3 & 900 & 5200 \\
\hline 1E & 15520 & 98.0 & 1100 & 7600 \\
\hline 2C & 11079 & 103.2 & 2750 & 5300 \\
\hline 3C & 13558 & 101.3 & 4700 & 6950 \\
\hline
\end{tabular}

Based on the results of finite element analysis, it can be said that the areas of the thin web plate affected by diagonal tension, which is the most critical from the maximal stress point of view, are located on the main diagonal near the edges. These areas are marked in Figure 13.

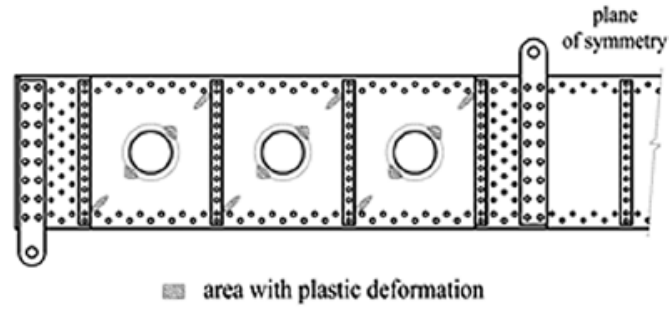

Fig. 13. Most critical areas of the web for diagonal tension

\section{Conclusion}

This paper is focused on experimental measurement and finite element analyses which were undertaken to determine the influence of circular web openings and a diagonal tension field on the ultimate shear strength of a thin beam web. The results which are presented in this paper are only one part of extensive research performed at the Institute of Aerospace Engineering, Brno University of Technology.

Based on the comparison of these results with those which were established according to various available analytical methods for calculation or sizing of such aircraft structures, decisions can be made about the accuracy and suitability of each analytical method for the sizing of thin beam webs with comparable parameters.

In addition, a lot of data which was registered during the practical experiment (strains in flanges and stiffener) together with the numerical models will be used for further analysis, which will be focused on the influence of the diagonal tension field on the additional load in flange, stiffeners and rivet joints.

\section{Dedication}

The research leading to these results has received funding from the MEYS under the National Sustainability Programme I (Project LO1202).

\section{References}

Čtverák, J.; Mertl, V.; Píštěk, A. 1997. Soubor podkladů pro pevnostní výpočty leteckých konstrukcí. Brno: LÚ FSI VUT Brno (in Czech).

Jebáček, I.; Horák, M. 2012. Possibilities and methods of in-flight loading measurement, Aviation 16(2): 47-50. ISSN 1648-7788.

Kuhn, P. 1942. The strength and stiffness of Shear web with round lightening holes having $45^{\circ}$ flanges. Report No. WR L-323. Washington: Langley Memorial Aeronautics Laboratory.

Kuhn, P.; Peterson, P.; Levin, L. 1952. A summary of diagonal tension, part I - methods of analysis. Report No. TN-2661. Washington: Langley Aeronautical Laboratory.

Maddux, G.; Vorst, L.; Giessler, F.; Moritz, T. 1969. Stress analysis manual. Report No. TI-219-69-24. Dayton: Technology Incorporated.

Niu, M. C. 1999. Airframe stress analysis and sizing. $2^{\text {nd }}$ ed. Hong Kong: Conmilit Press Ltd. ISBN 962-7128-08-2.

Píštěk, A.; Grégr, O.; Kahánek, V.; Böhm, R. 1988. Pevnost a životnost letadel I. Brno: Vysoké učení technické v Brně (in Czech).

Singer, J.; Arbocz, J.; Weller, T. 2002. Buckling experiments: experimental methods of buckling of thin-walled structures. Vol. 2. New York: John Wiley \& Sons, Inc. ISBN 0-471-97450-1. 